\title{
OPTIMIZATION OF FIELD TOPOGRAPHY IN SURFACE IRRIGATION
}

César González-Cebollada ${ }^{1}$, David Moret-Fernández² ${ }^{2}$ Irene Buil-Moure ${ }^{3}$ and Víctor MartínezChueca $^{4}$

1 Professor, University of Zaragoza. Carretera de Cuarte s/n 22071 Huesca, Spain.

2 Ph.D. Agronomical Engineer, Spanish Research Council, EEAD Avda Montañana 1005, 50059 Zaragoza, Spain.

3 Agronomical Engineer, University of Zaragoza. Carretera de Cuarte s/n 22071 Huesca, Spain 4 Agronomical Engineer, University of Zaragoza. Carretera de Cuarte s/n 22071 Huesca, Spain

\section{Corresponding author:}

Dr. César González Cebollada

Postal adress: EPS Carretera de Cuarte, s/n, 22197 Huesca, Spain

Telephone number: (+34) 974292660

E-mail: cesargon@unizar.es

\section{ABSTRACT}

This work presents and applies a new methodology to find the optimal topography of a surface irrigation field, achieving a theoretically uniform surface irrigation.

For any variant on surface irrigation (basin, border or furrow, with open or blocked end), the method's result is a particular curved topographical shape of a field. This shape distributes water evenly over the field, so that distribution uniformity is theoretically $100 \%$ and deep percolation disappears.

The methodology is applied to two theoretical cases: a 1-D blocked-end field and a 2-D square field with corner inflow. For each case, the methodology reaches a particular topography where distribution uniformity is near $100 \%$.

To put into practice this methodology, the optimized topography (which has a curved shape) must be approached to a set of slopes. A real example is shown where a real field was laser-levelled with two consecutive slopes to fit the optimized topography, previously calculated with the methodology here presented. The irrigation was evaluated before and after the optimization. The results indicate an increase of distribution uniformity from $82 \%$ to $96 \%$. 
36 The topographic optimization methodology offers new information about topography influence on

37 irrigation performance indicators, and main practical conclusion is that this method can be useful to

38 determine the best slope, set of slopes or curved shape when levelling any field for surface

39 irrigation, in order to get a uniform surface irrigation.

\section{INTRODUCTION AND OBJECTIVES}

In surface irrigation, most water loss at the plot level is from deep percolation (and surface runoff

44 when end field is open). In general, surface irrigation is not uniform because the areas nearest the water entry point receive more water. In any variant of surface irrigation (basin, border or furrow, with open or blocked end), the distribution is less uniform than with pressurised irrigation systems

47 (FAO 2002; Walker and Skogerboe 1987). At present, to improve surface irrigation uniformity there are several techniques: drainback, adjusting cutoff time or inflow rate, surge flow, cablegation, inflow cutback, runoff reuse, adjusting design (length, width), zero-leveling and, finally, leveling with slope (Walker and Skogerboe 1987, Hoffman et al. 2007).

Due to the increasing water scarcity due to climate change or population growth, the modern

53 levelling techniques available for irrigated plots (laser, Global Positioning System GPS) justify

54 studying the influence of the field surface topography on irrigation uniformity (Playán et al. 1996).

56 A small slope in the advance direction can improve performance (Khanna and Malano, 2006), and

57 the selection of best slope requires careful analysis for every case (Khanna et al., 2003). In one-

58 dimensional approach, this best slope can be obtained with a simulation tool, as SIRMOD (Walker, 59 1998) or WinSRFR (Bautista et al., 2015). or with non-dimensional graphs (González-Cebollada et al., 2011). In the other hand, the system becomes increasingly sensitive to inputs when slope 
61 increases, and management problems are often proportional to the longitudinal slope (Playán, 62 2006).

63 The best slope is very useful in practice because it maximizes the distribution uniformity under 1-D

64 approach. To improve the uniformity even more, it is necessary to use more than one slope, or to 65 leave the 1-D approach with a 2-D conception. In these cases, there are not practical tools to find 66 out easily the best topographical configurations. In the limit, the existence of a particular curved 67 topography with theoretical 100\% uniformity can be conjectured for each particular case, but there 68 is no way to calculate it until now.

69 The objective of this work is to present and apply a method which lets us find the best curved 70 topography of a field to help distribute the water uniformly over the field, getting a theoretical 71 distribution uniformity of $100 \%$. It can be applied to any surface irrigation system (basin, border or 72 furrow; open or closed contours; 1-D or 2-D) under realistic conditions.

73 For each particular case, optimal topography will depend on the infiltration parameters, the

74 Manning's roughness coefficient, the flow rate, the geometry of the field and the water required 75 depth.

76 The results obtained with this method can be adjusted in practice with one or more slopes or planes,

77 leading to more precise configurations than the configurations obtained with a 1-D single slope 78 approach, to avoid water loss through deep percolation as much as possible.

\section{METHODOLOGY}

82 To reach the proposed objective, a new methodology was developed to find a theoretically perfect

83 topography for each particular case. This methodology, through an iterative process, leads to a

84 curved ground surface which in theory obtains 100\% distribution uniformity $(D U)$ without deep 85 percolation $(D P)$ in any variant of surface irrigation (basin, border or furrow, with open or blocked 
end). Distribution uniformity is defined here as the quotient between minimum infiltration and

87 average infiltration.

89 The method is computational and iterative. It needs hydraulic simulation software. The infiltration

90 parameters, the Manning's roughness coefficient, the flow rate, the geometry of the field and the

91 water required depth must be known, and wave model (complete, diffusive, kinematic), time step

92 and space step must be properly selected. Some of these parameters can vary throughout time, so

93 average values must be used. Spatial variations of infiltration parameters or Manning coefficient

94 can be considered in the simulation software or can be averaged. The method starts simulating a

95 horizontal topography (zero levelled) of the field which is going to be optimized. Each simulation

96 let us to know where there is more infiltration and where there is less infiltration.

98 In each iteration of the method, the more infiltration point is raised (to decrease its infiltration), and 99 the less infiltration point is lowered (to increase its infiltration). These elevation changes are made 100 in the computational model. Then, a new hydraulic simulation is run, adjusting the irrigation time so 101 that minimum infiltration $\left(z_{\min }\right)$ coincides with the required depth $\left(z_{r e q}\right)$. In this new situation, the 102 new more infiltration point is detected to be raised in the next iteration, and the new less infiltration 103 point is detected to be lowered in the next iteration.

105 The iterative repetition of these operations leads to an evolution of the ground topography until a 106 particular curved shape where theoretically perfect water distribution uniformity is reached. Each 107 step of this computational methodology is given below.

109 Step 1: Read data. Data are: infiltration parameters, Manning's coefficient, water flow rate, field 110 geometry and required depth. In the case of furrow irrigation, the corresponding geometric 111 parameters must also be known. The initial topography of the field is considered to be horizontal. 
113 Step 2: Adjust irrigation time and calculate. Using a hydraulic simulation tool, adjust the

114 irrigation time by trial and error until minimum depth matches required depth. Then, detect the 115 point in the field with more infiltration and the point with less infiltration. Evaluate distribution 116 uniformity.

118 Step 3: If the irrigation is uniform, stop. When distribution uniformity reaches a desired value 119 (99\% for example), the process ends, and the optimal topography has been reached.

121 Step 4: Raise the point of greatest infiltration. The level of the point with more infiltration is 122 raised to reduce its infiltration.

124 Step 5: Lower the point of least infiltration. The level of the point with less infiltration is lowered 125 to increase its infiltration.

127 Step 6: Go to step 2. Going to the step 2, the loop of the iterative process is closed, adjusting again 128 the irrigation time with the new topography derived from steps 4 and 5.

130 Figure 1 shows this procedure in a flow chart. Note that each loop requires several simulations, 131 because irrigation time must be adjusted by trial and error. 


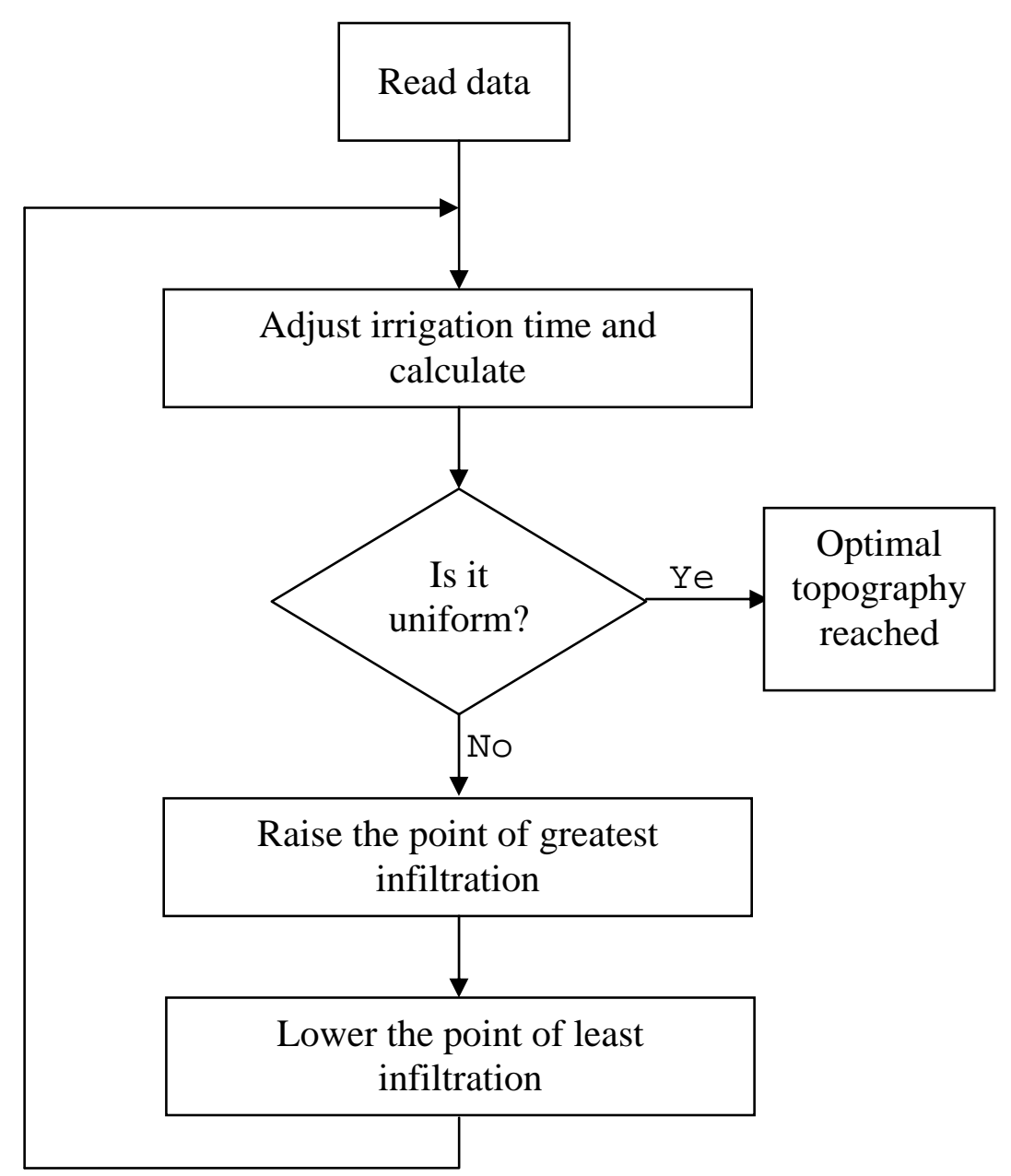

Figure 1. Flow chart to reach the optimal topography in surface irrigation.

This computational and iterative process tends to improve distribution uniformity by topographical

164 modifications, assuming that the flow rate is higher than a minimum value that can be calculated.

165 Theoretically, the final curved shape of the field is $100 \%$ uniform, including open-end surface

166 irrigation fields. In practice, the optimized topography could be adjusted to a set of planes by means 167 of laser levelling or other levelling techniques. 
171 The methodology has been applied to two surface irrigation cases: a 1-D blocked-end field and a 2-

172 D square field with corner inflow.

173

174 Case 1: One-dimensional blocked-end field.

175

176 This first test case has been extracted from Dholakia et al. (1998). The field is 185.9 m length, with

$17710.93 \mathrm{l} / \mathrm{s} / \mathrm{m}$ inflow rate. Required depth is 100 millimeters (mm), Manning coefficient is $0.1 \mathrm{~s} / \mathrm{m}^{1 / 3}$

178 and Kostiakov infiltration function is $\mathrm{z}=73.72 \cdot \mathrm{t}^{0.6}$, where $\mathrm{z}$ is the infiltration depth in $\mathrm{mm}$ and $\mathrm{t}$ is

179 time in hours (Kostiakov, 1932).

180 We used POZAL software for this first case, which automatically concludes the iterative process in

181 about 14 minutes with a standard computer, with about 200 iterations. POZAL software was

182 specifically developed for this work and applies the complete hydraulic model of the one-

183 dimensional equations of free surface flow (Saint-Venant equations), using the finite differences

184 method according to the MacCormack scheme (Dholakia et al. 1998; García-Navarro et al. 1992),

185 by dividing the field into 100 equal parts. More popular programs, like WinSRFR (Bautista et al.

186 2015) or SIRMOD (Walker, 1998) could be used here instead of POZAL. In that case, the iterative

187 process must be applied manually, taking a few hours of work.

189 Figure 2 shows the results of this case in three different graphs: the first shows the evolution of 190 distribution uniformity, cut-off time and deep percolation throughout the iterative process of the 191 methodology; the second graph shows the advance-recession diagram for the initial (zero slope) and 192 final (optimized topography) situations of the process; the third graph shows the final topography of 193 the optimized field, and the infiltration process with the optimized topography, together with the 194 final infiltration topography when there is no slope. 


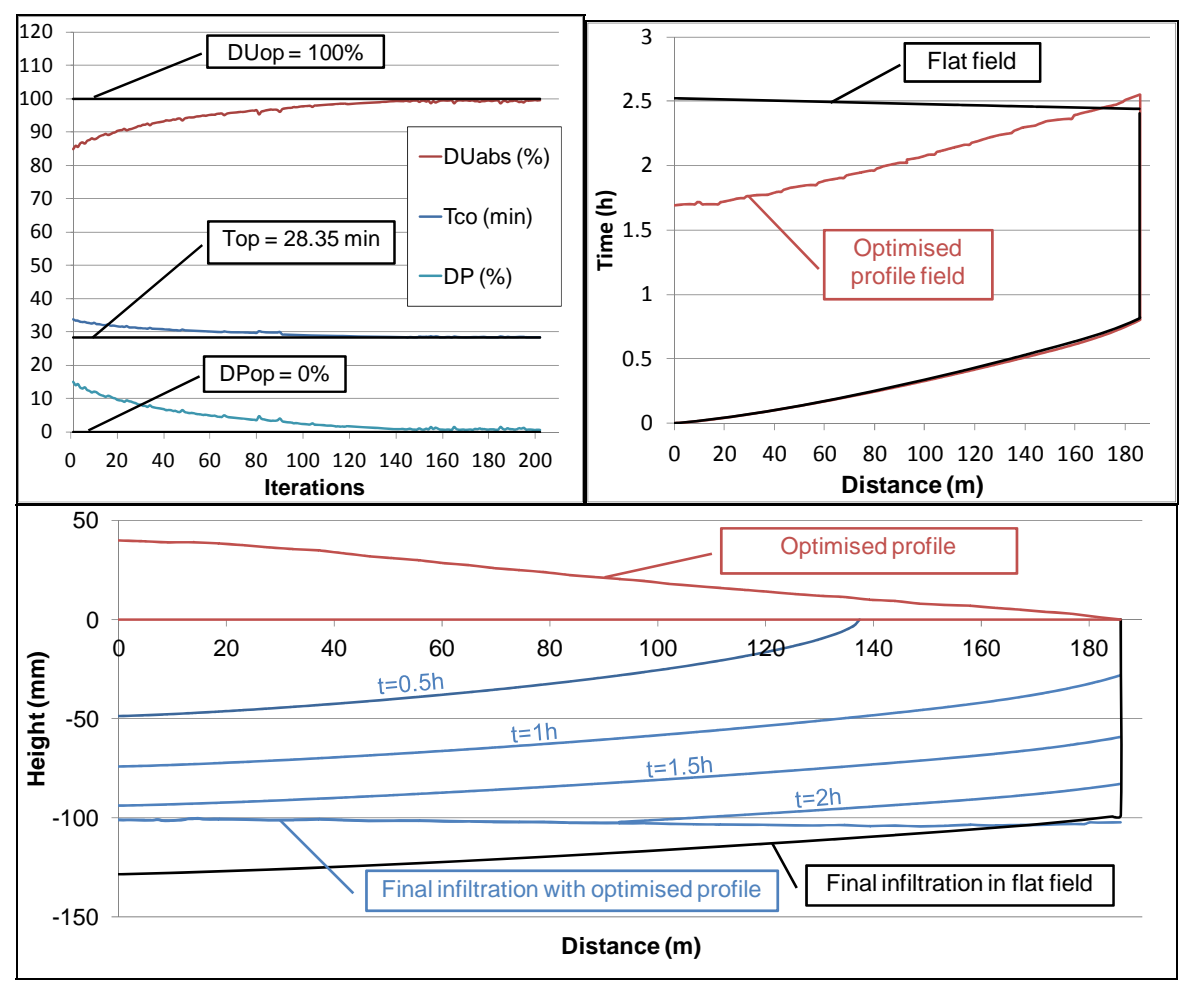

199 Figure 2. Case 1: evolution of indicators, advance-recession diagram and final profiles.

201 Note the parallelism between the advance curve and the recession curve of the optimized

202 topography. This indicates that the opportunity times of all the points are similar, so infiltrations are 203 similar. This leads to the practically horizontal final infiltration profile, coinciding with the required 204 depth, as observed in the third graph of Figure 2.

206 Before, distribution uniformity was $85.3 \%$, with the best slope is $95.0 \%$ and after the optimization it 207 increases to $99.4 \%$. Deep percolation disappears in practice (from $14.7 \%$ to $0.6 \%$ ) and time and 208 water saving are $13.1 \%$ after the optimization.

210 Case 2: Square field with a corner inflow. 
212 Second example deals with a corner inflow in a square field. It's a two-dimensional case, solved

213 with the help of the B2D programme, published by Utah State University, USA (Playán et al.

214 1994a, 1994b).

215 The field is a 90x90m square, with $200 \mathrm{l} / \mathrm{s}$ inflow rate and 60mm required depth. Manning

216 coefficient is $0.04 \mathrm{~s} / \mathrm{m}^{1 / 3}$ and the infiltration is adjusted by $\mathrm{z}=251.96 \mathrm{t}^{0.504}+7.02 \mathrm{e}-4 \mathrm{t}$.

217 Again, the methodology eliminates practically all deep percolation and raises DU to 100\% (first

218 graph of Figure 3). The ground topography evolves until a final topography shown in the second 219 graph of Figure 3, with an average slope of $0.027 \%$.
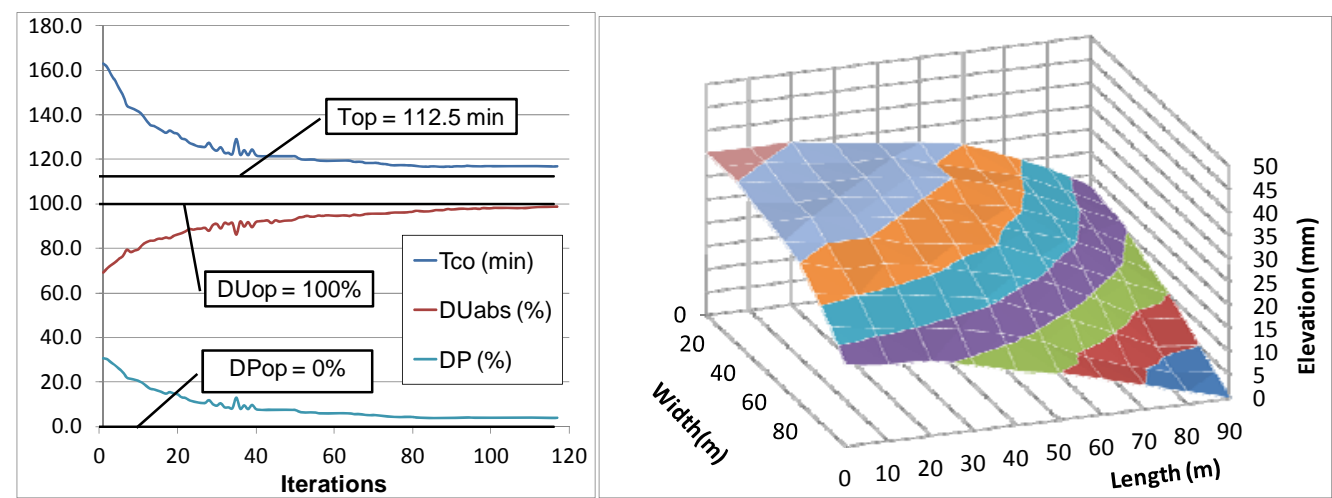

Figure 3. Case 2: evolution of indicators and optimized field topography.

225 Figure 4 shows the three-dimensional representation of the evolution of water depth (first column)

226 and infiltration depth (second column) over the length and width of the field in five different,

227 evenly spaced instants: at the start, a quarter of the total time, half the total time, three quarters of

228 the total time, and end. Again, we observe homogeneous infiltration thanks to the new field

229 topography. Water level (water depth, first column) shows the water storage in the lower points that 230 increases the distribution uniformity. 


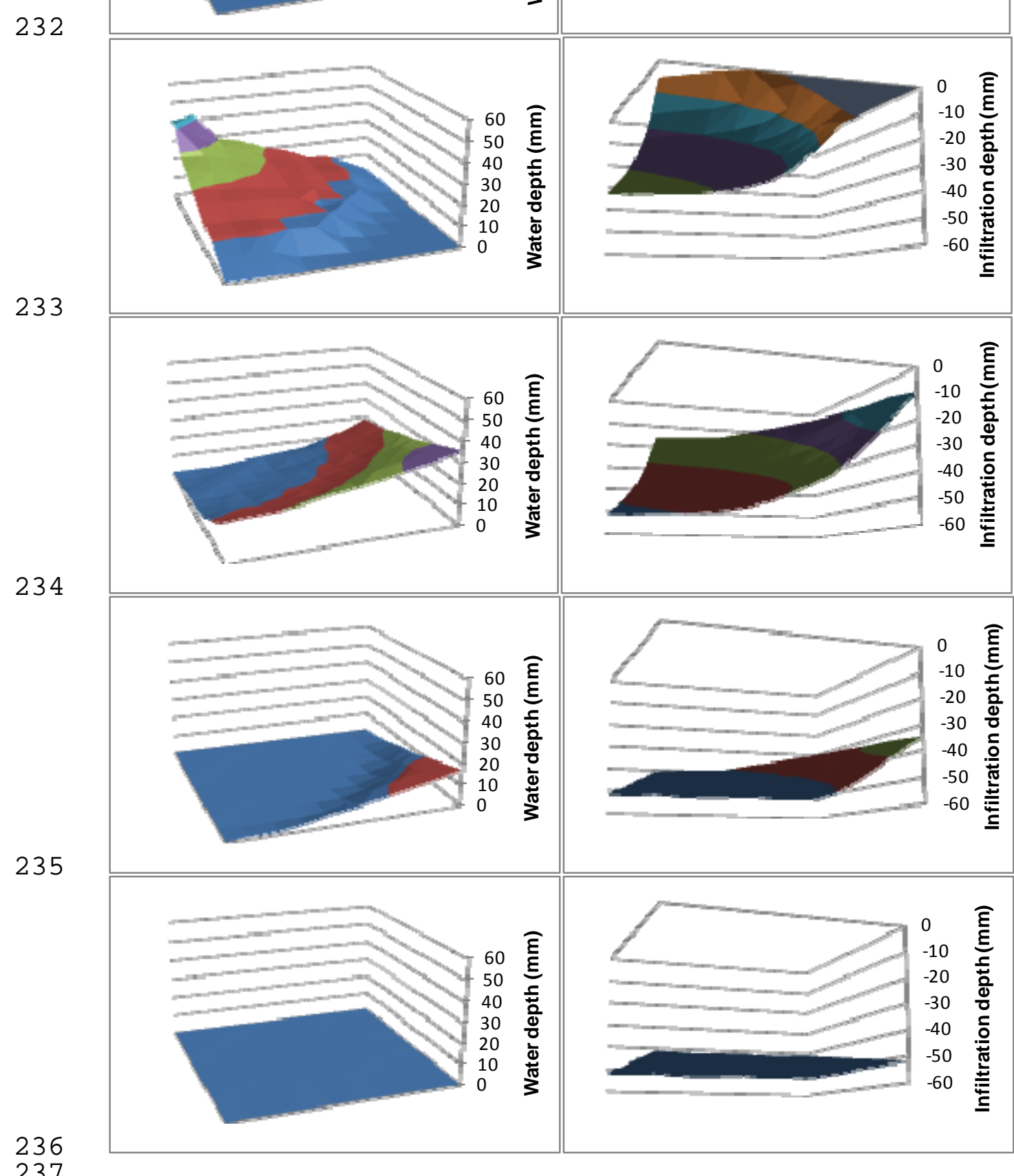

238 Figure 4. Case 2: evolution of depth and infiltration for $t=1 \mathrm{~min}, t=63.2 \mathrm{~min}, t=126.1 \mathrm{~min}$,

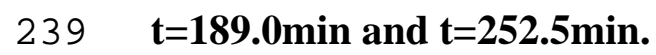


241 Before, distribution uniformity was 70.9\%, and after the optimization it increases to 98.5\%. Deep

242 percolation decreases from $29.0 \%$ to $1.2 \%$ and time and water saving are $11.2 \%$ after the

243 optimization.

\section{FIELD VALIDATION.}

247 To validate the method of topographic optimization, a field test was conducted in a plot located in 248 Almudévar (Huesca, Spain). The plot is 100 meters long by 26 meters wide, and it is irrigated with 249 a constant flow rate of $47 \mathrm{l} / \mathrm{s}$ from one end of the plot, which is considered a one-dimensional 250 irrigation, with blocked end. The infiltration function was experimentally determined by cylinder 251 infiltrometers, with measurements in the center of each half of the field that were averaged, yielding $252 \mathrm{z}=79.95 \cdot \mathrm{t}^{0.5837}$, where $\mathrm{z}$ is infiltration depth in $\mathrm{mm}$ and $\mathrm{t}$ is time in hours. Soil moisture was low 253 enough and the soil was bare (Manning coefficient $0.04 \mathrm{~s} / \mathrm{m}^{1 / 3}$ ). The micro-topography was not 254 measured.

255 Two irrigation trials were conducted:

256 1. Before: Plot leveled without slope.

257 2. After: Plot leveled with two consecutive slopes. The first half of the plot leveled with $0.12 \%$ 258 slope and the second half with $0.07 \%$ slope. These two slope values were obtained by a least 259 squares fit of the results obtained with topographical optimization method described in this article. Figure 5 shows the optimal topography obtained with the computer applying the methodology here presented and the two- slopes approach. The position of the slope change point could be optimized with the adjust, which could be object of further research. 


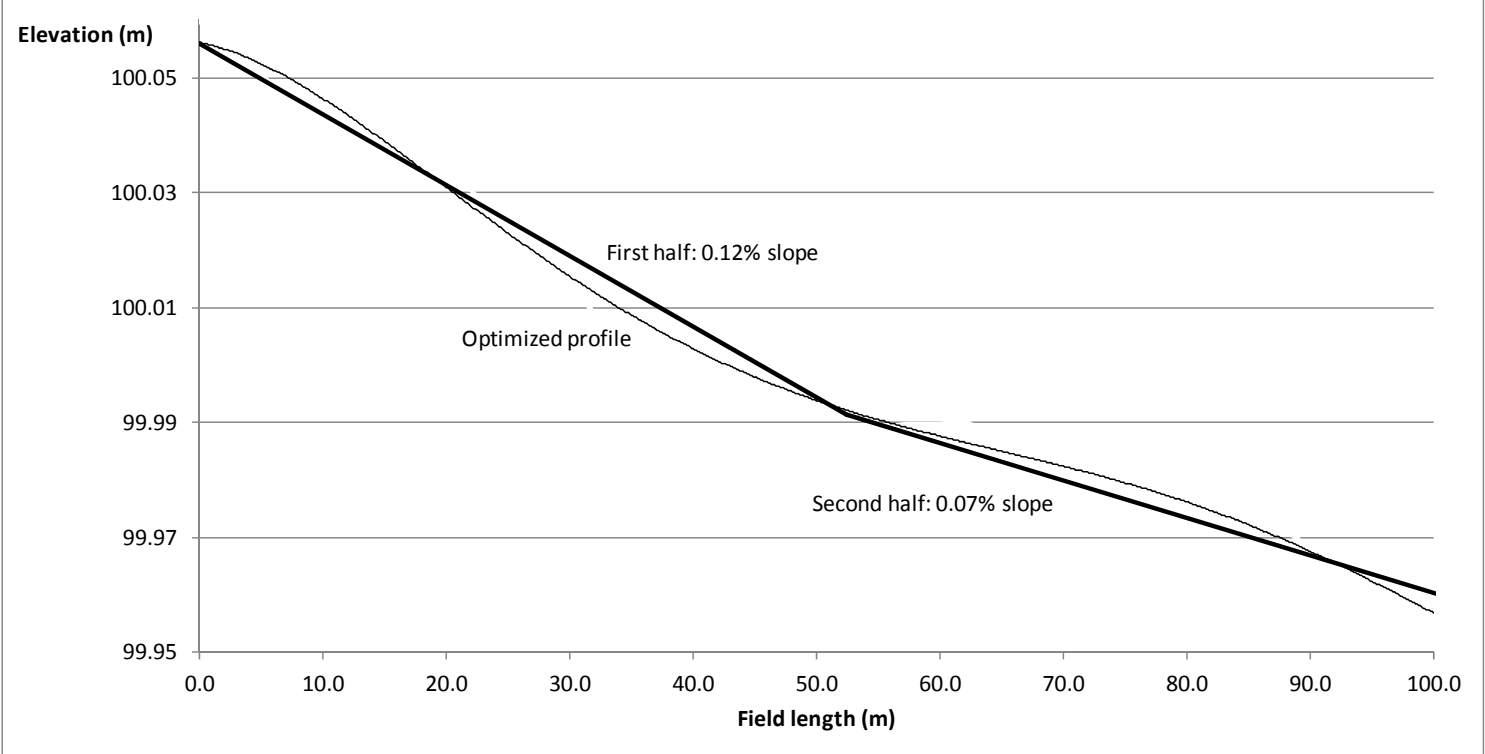

266 Figure 5. Field validation: optimized topography and two-slopes fit.

268 In each trial, $344 \mathrm{~m}^{3}$ of water were applied to the field, which means an average infiltration of 132 $269 \mathrm{~mm}$ of water. Throughout the plot, 11 measuring stations were located (every ten meters), and the 270 advance and recession times were recorded in each of them. Then, opportunity time and infiltration

271 depth was calculated at each station.

273 In the results, we observe that the topographic optimization improved irrigation uniformity. Figure

2746 indicates a more uniform infiltration, despite the existence of a slight flooding at the end of the 275 first half of field, which could be due to a slight inaccuracy in connecting the two slopes. 


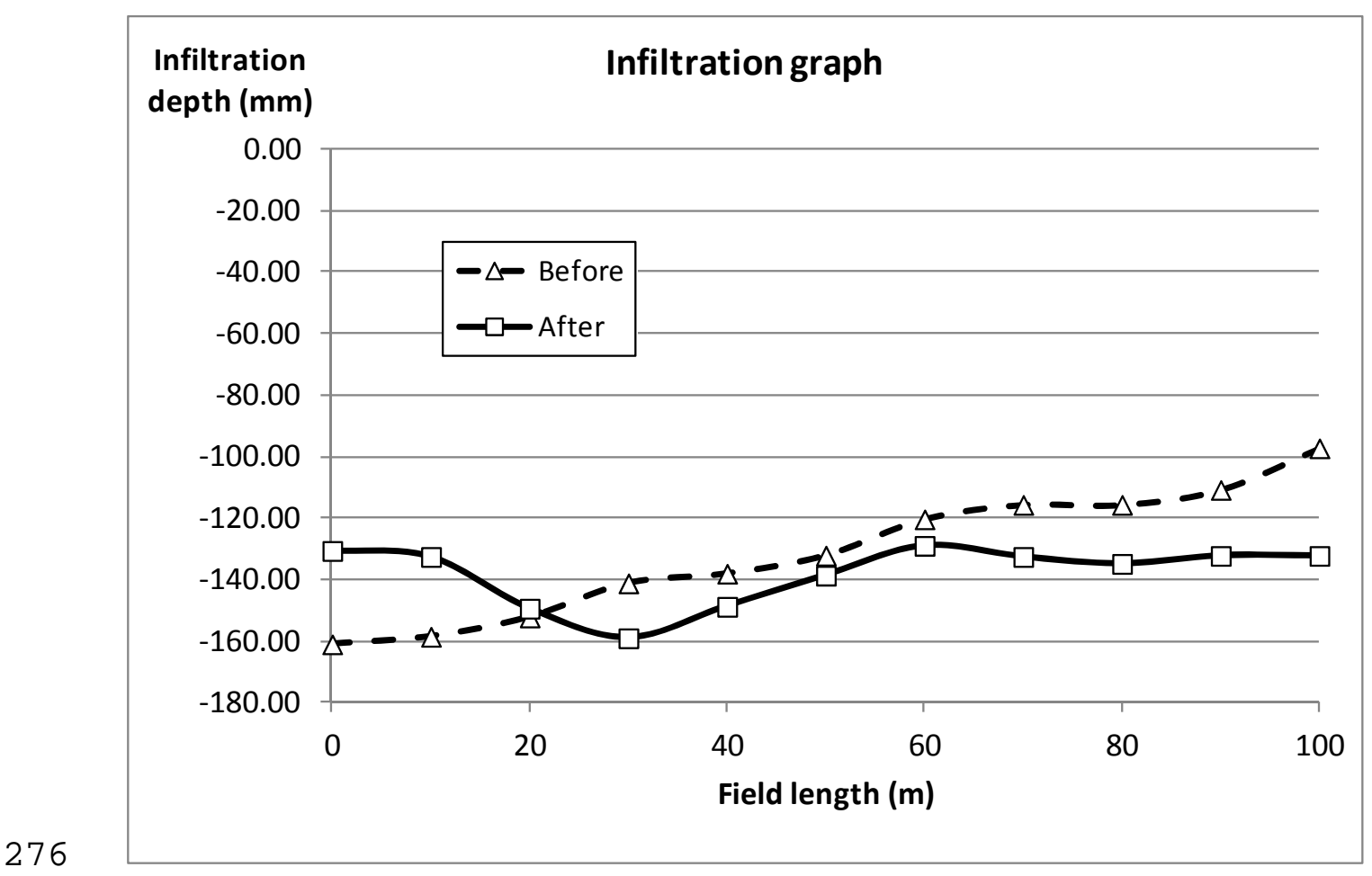

278 Figure 6. Field validation: infiltration before and after the topographic optimization.

280 Figure 7 is the advance-recession graph, and shows a faster advance of the water thanks to the 281 topographic optimization, and a greater parallelism between advance and recession curves, 282 indicating opportunity times more homogeneous. 


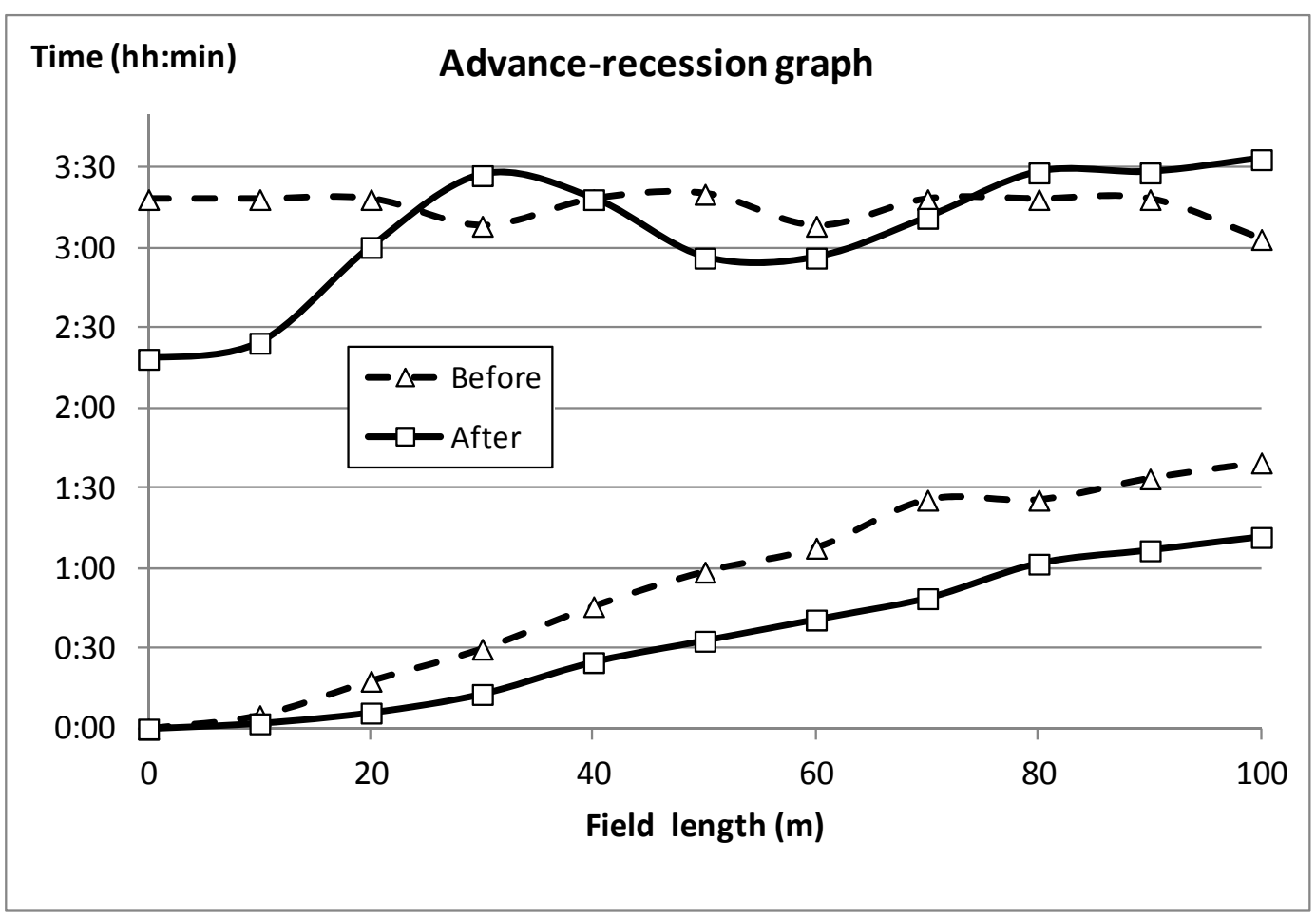

Figure 7. Field validation: advance and recession before and after the topographic optimization.

Table 1 provides the main indicators of distribution uniformity, calculated before and after the topographic optimization.

\begin{tabular}{|c|c|c|c|}
\hline $\begin{array}{c}\text { Uniformity } \\
\text { Distribution }\end{array}$ & Definition & Before & After \\
\hline $\mathrm{UD}_{\mathrm{abs}}$ & $\begin{array}{c}\text { mínimum infitration / } \\
\text { average infiltration }\end{array}$ & $74.1 \%$ & $93.3 \%$ \\
\hline $\mathrm{UD}_{\mathrm{lq}}$ & $\begin{array}{c}\text { low quarter minimum } \\
\text { infiltration / average } \\
\text { infiltration }\end{array}$ & $82.3 \%$ & $96.3 \%$ \\
\hline
\end{tabular}

Table 1. Experimental validation: uniformity indicators before and after the topographic optimization.

294 In general, an important improvement in distribution uniformity is observed, which would likely 295 have been even higher without the slight inaccuracy in connecting the two slopes. 
297 Figure 8 compares the data collected and the results of WinSRFR model. Some differences can be 298 observed, associated to the variability of the parameters (Manning, infiltration coefficients, flow 299 rate...) and to the practical difficulties to connect properly the two slopes or to determine the 300 moment of the end of the infiltration in each station.

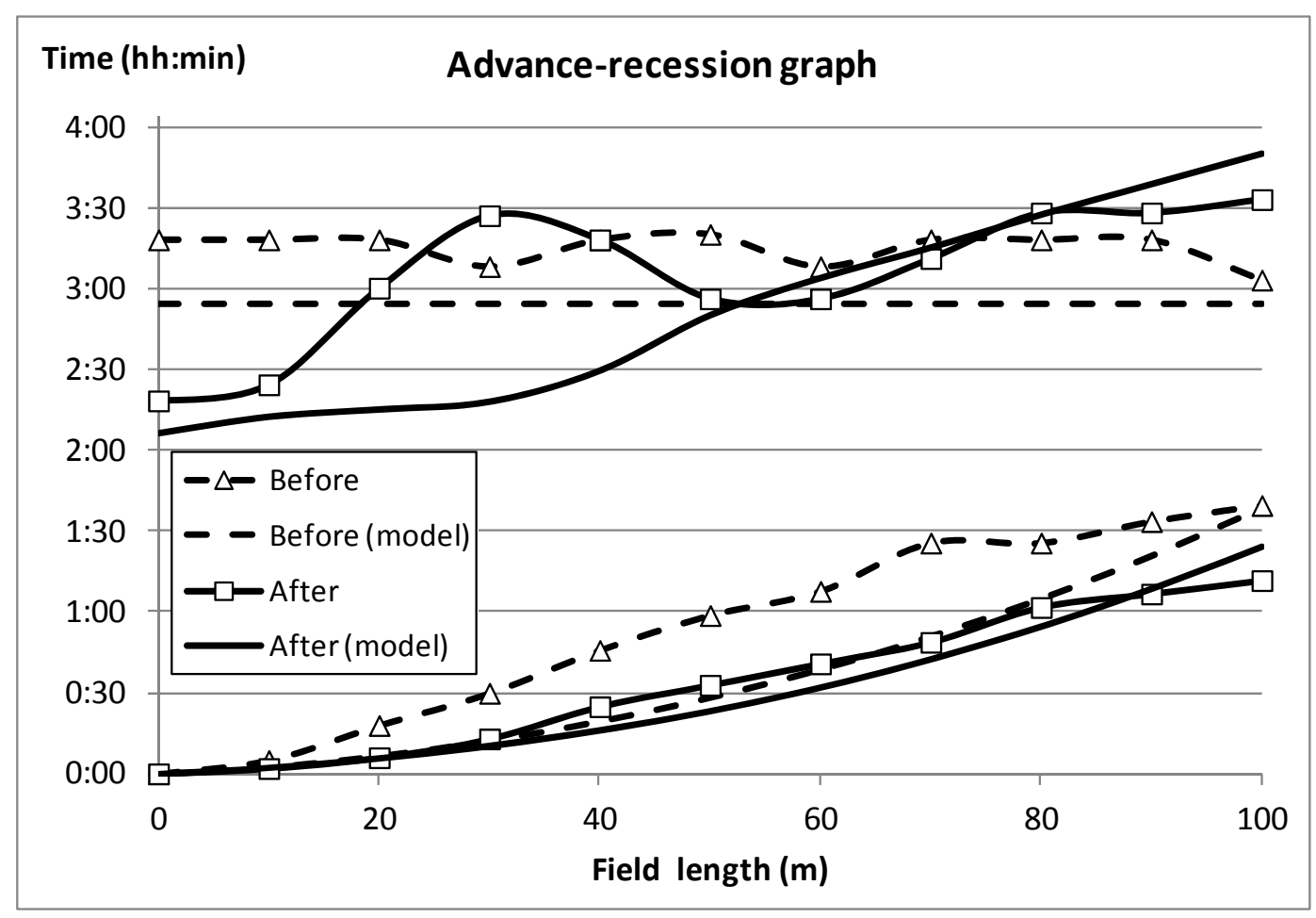

Figure 8. Advance and recession: experimental results and model results.

305 Finally, Table 2 shows the differences in low quarter distribution uniformity between theory and 306 practice in this study case. As in Figure 8, theoretical results have been obtained with WinSRFR 307 software. 


\begin{tabular}{|c|c|c|}
\hline Topography & Practice & Theory \\
\hline Zero slope & $82.3 \%$ & $86.0 \%$ \\
\hline One slope & - & $97.6 \%$ \\
\hline Two slopes & $96.3 \%$ & $98.0 \%$ \\
\hline Optimized & - & $100 \%$ \\
\hline
\end{tabular}

Table 2. Experimental validation: Low quarter DU values in practice and in theory under different topographical configurations.

Obviously, the experimental results are worse than the theoretical results, but both show significant improvements introduced by the topography optimization. In this case, one single slope gets $97.6 \%$ in theory and double slope gets $98 \%$. As the experimental field used in this validation is small, there are no significant differences between one or two slopes in this case. But in a long field, or a wider field, or a non-rectangular field, these differences could be appreciable and the topographical optimization could open new levelling possibilities (not only with two longitudinal slopes) with better uniformity and with no additional cost in comparison to one single slope leveling.

SENSITIVITY ANALYSIS.

324 Throughout an irrigation season, the main parameters can vary notably, which harms the robustness 325 of the optimized topography (of the sloping irrigation in general). The sensitivity of the optimized topography to parameters variation has been evaluated theoretically in the previous field validation 
case. Starting from an ideal situation (optimized topography with 100\% uniformity), when flow rate

328 decreases $10 \%$, low quarter distribution uniformity decreases to $95 \%$, and when flow rate increases

$32910 \%$, uniformity decreases to $92 \%$. When infiltration decreases $10 \%$, uniformity is $86 \%$, and when

330 infiltration increases $10 \%$, uniformity is $93 \%$. When Manning coefficient doubles, uniformity is

$33197 \%$. Finally, when required depth decreases 10\%, uniformity is $96 \%$ and when required depth

332 increases $10 \%$, uniformity is $94 \%$.

CONCLUSIONS.

From a strictly theoretical point of view, the main conclusion is that the presented method achieves uniform surface irrigation, optimizing the topography of the field. In the cases analyzed, computational and real, the method achieves the main objective of getting distribution uniformity near $100 \%$. As minimum infiltration depth matches required depth, deep percolation disappears.

341 In many cases, particularly when the 1D approach can be applied and the fields are not too long, a 342 single slope calculated by trial and error with conventional software can be enough to reach a high 343 uniformity. In the Case 1, uniformity with one slope was $95.0 \%$ and in the field validation was $34497.6 \%$. These values are close to $100 \%$ of topographical optimization. In these cases, a two-slope 345 configuration doesn’t provide a significant improvement and probably it isn’t worth to optimize the 346 topography. Besides, it is important to remark that important parameters are considered constant in 347 theory, but, in real irrigation, infiltration parameters, Manning coefficient and flow rate can vary 348 throughout space and/or time in an irrigation season. The variation of uniformity due to this 349 variability can be greater than the improvement on uniformity due to two-slopes configuration 350 instead of one slope configuration. The optimal topography is calculated for a fixed required depth, 351 but it can vary too, depending on the needs of the crop and the soil. For this reason, the optimal 
352

353

354

355 356

topography should be calculated for the most frequent required depth, and other parameters should be properly averaged.

The sensitivity analysis confirms these considerations, showing an important influence of flow rate and infiltration function in the real uniformity, and a minor influence of Manning coefficient. The analyzed case suggests that low infiltration values, high flow and high required depth rate values should be considered in the topography optimization.

In any case, the optimized topography offers new information about topography influence on irrigation performance indicators, which can be useful when levelling a field with no-zero slope. The number of slopes and the position of the slope changes are parameters that can be analyzed in depth after topographic optimization. The knowledge of the shape of the topographic optimization can help us to make decisions about it. So, optimized topography can be useful:

- To give an optimal slope to a field. When levelling a field, it is interesting to know the theoretical optimal slope. It could be known with simulation models or with graphs, but only with one-dimensional approximation. With this method, any case can be solved.

- To give two or more slopes to a field. Knowing the optimal topography, it is easy to adjust a set of slopes, bringing the field near to its optimal form, including $2 \mathrm{D}$ cases.

- To give a curved topography to a field. It is technically more difficult, but it is the more efficient option and theoretically makes deep percolation disappear, getting theoretical uniform surface irrigation. 
377 Finally, optimized topography can be useful to better understand the relationship between

378 topography and efficiency indicators in surface irrigation, and their sensitivity to parameters

379 variation.

\section{AKNOWLEDGES}

383 This work was supported by the Government of Aragón (Spain) and the European Social Fund 384 (European Union).

\section{REFERENCES}

Bautista E., Shclegel J.L., Clemmens J. (2015). “The SRFR 5 modeling system for surface irrigation”. Journal of Irrigation and Drainage Engineering. DOI:10.1061/(ASCE)IR.19434774.0000938.

Dholakia M., Misra R., Zaman M.S. (1998). “Simulation of border irrigation system using explicit MacCormack finite difference method”. Agric. Water Manag. 36(3):181-200.

FAO (2002). Irrigation manual - planning, development, monitoring and evaluation of irrigated agriculture with farmer participation. Food and Agriculture Organization of the United Nations, Harare, Zimbabwe.

García-Navarro P., Alcrudo F., Savirón J.M. (1992). “1-D Open-channel flow simulation using 398 González-Cebollada, C., Cervera, L., Moret-Fernández, D. (2011). "Basin irrigation design with 399 longitudinal slope”. Agric. Water Manag. 98 (2011) 1516- 1522.

$40 \odot$ Hoffman, G.J., Evans R.G., Jensen M.E., Martin D.L., Elliot R.L. (2007). Design and operation of 401 farm irrigation systems. American Society of Agricultural and Biological Engineers. ISBN 1402 892769-64-6. 
403 Khanna M., Malano, H.M., Fenton, J.D., Turral H. (2003) “Design and management guidelines for 404 contour basin irrigation layouts in southeast Australia”. Agric. Water Manag. 62(2003):19-35. 405 Khanna M.,Malano H.M. (2006). “Modelling of basin irrigation systems: A review”. Agric. Water 406 Manag. 83(2006)87-99.

407 Kostiakov A.N. (1932). "On the dynamics of the coefficient of water-percolation in soils and on the 408 necessity for studying it from a dynamic point of view for purposes of amelioration”. Trans. 409 Sixth Comm. Intl. Soil Sci. Soc., Russian Part A:17-21.

410 Playán E., Walker W.R., Merkley G.P. (1994a). “Two-dimensional simulation of basin irrigation. I: 411 Theory”. J. Irrig. Drain. Eng. 120(5):837-856.

412 Playán E., Walker W.R., Merkley G.P. (1994b). “Two-dimensional simulation of basin irrigation. 413 II: Applications”. J. Irrig. Drain. Eng. 120(5):857-870.

414 Playán E., Faci J.M., Serreta A. (1996). “Characterizing microtopographical effects on level-basin 415 irrigation performance”. Agric. Water Manag. 29(2):129-145.

416 Playán, E. (2006). “Design, operation, maintenance and performance evaluation of surface 417 irrigation methods”. International course on land and water resources management: irrigated 418 agriculture. Istituto Agronomico Mediterraneo-CIHEAM, Bari, Italy.

419 Walker W.R., Skogerboe G.V. (1987). Surface irrigation. Theory and practice. Prentice-Hall, $420 \quad$ Englewood Cliffs, NJ, USA.

421 Walker W. (1998). SIRMOD - Surface Irrigation Modeling Software. Utah State University, USA. 